\title{
Performance of sesame straw cellulose, hemicellulose, and lignin biochars as adsorbents in removing benzo(a)pyrene from edible oil
}

\author{
Qiao-Li YANG ${ }^{1}$, Zhao QIN ${ }^{1 *}$ (D), Hua-Min LIU ${ }^{1}$, Xi-Chuang CHENG ${ }^{1}$, Yu-Xiang MA ${ }^{1}$, Xue-De WANG ${ }^{1 *}$
}

\begin{abstract}
The safety problems related to the occurrence of benzo(a)pyrene in edible oil have been a major threat to human health, and now significant attention has been to remove benzo(a)pyrene. So in this work, cellulose, hemicellulose, and lignin biochars were prepared, and then were used to remove benzo(a)pyrene from contaminated oil. Based on the nitrogen adsorption/desorption isotherms and the scanning election micrographs, the modified biochars had a huge specific surface area of $983.50-1915.55 \mathrm{~m}^{2} / \mathrm{g}$ and a well-developed porous structure. The modified biochars showed higher removal rate for benzo(a)pyrene than unmodified biochars. The highest adsorption (95.79\%) of benzo(a)pyrene was achieved using the modified lignin biochar, which was therefore selected for evaluation of adsorptive capacity. The ability of the modified lignin biochar to adsorb benzo(a)pyrene was consistent with the pseudo-second order kinetic equation indicating mainly chemisorption, and it fit the Freundlich isotherm $\left(\mathrm{R}^{2}>0.999\right)$, thereby revealing the occurrence of multilayer adsorption. The effect of $\pi-\pi$ conjugation interaction and pore-filling together promoted the high adsorption performance of the modified lignin biochar. This work demonstrates that the modified lignin biochar could be a promising adsorbent for the removal of benzo(a)pyrene from edible oils.
\end{abstract}

Keywords: benzo(a)pyrene; biochar; edible oil; removal; $\mathrm{ZnCl}_{2}$.

Practical Application: The effect of $\mathrm{ZnCl}_{2}$-modified biochars from cellulose, hemicellulose and lignin obtained from sesame straw on benzo(a)pyrene removal from edible oil was investigated. The removal process, mechanism of benzo(a)pyrene on the biochar was studied. This study provides a promising adsorbent for the removal of benzo(a)pyrene from edible oils.

\section{Introduction}

Benzo(a)pyrene $(\mathrm{BaP})$ is a polycyclic aromatic hydrocarbon (PAH) and a well-known carcinogen (Shi et al., 2017; Shin et al., 2016). $\mathrm{BaP}$ has been shown to cause carcinogenic, teratogenic, mutagenic, and cytotoxic effects in various tissues and cell types (Moserová et al., 2009). Due to its toxicity and mutagenicity, the International Agency for Research on Cancer (IARC) upgraded $\mathrm{BaP}$ from Group 2A (probably carcinogenic to humans) to Group 1 (carcinogenic to humans) (Cheng et al., 2015). BaP is present in a wide variety of food items, such as smoked foods (Rhee \& Bratzler, 1970), edible oil (Camargo \& Toledo, 2000), coffee, fried foods, and meat products (Wu et al., 2020). In particular, edible oil can be heavily contaminated with BaP, because of their strong lipophilic property and wide distribution in the environment (Shi et al., 2017; Cotugno et al., 2021). $\mathrm{BaP}$ in edible oil originated from various factors including the environmental pollution of raw materials, seeds drying on asphalt road surfaces, and production during the processing of edible oils (Cotugno et al., 2021). To date, peanut (Ji et al., 2020), sesame (Ji et al., 2019), olive (León-Camacho et al., 2003), and rapeseed oils (Rojo Camargo et al., 2012) have been reported to contain relatively high concentrations of BaP. Now, China has set a legal limit of $10 \mu \mathrm{g} / \mathrm{kg}$ for BaP content in edible oils, and the European Commission has established the maximum levels for BaP was $2 \mu \mathrm{g} / \mathrm{kg}$ (Ji et al., 2020; Kazerouni et al., 2001). Therefore, how to remove $\mathrm{BaP}$ in edible oils effectively is a critical issue in the field of food safety.

Various technologies, such as coagulation, adsorption, flocculation, sedimentation, filtration and ozonation have been emerged for the BaP removal (Xi \& Chen, 2014; Yang et al., 2019). Among these, adsorption is effective, and is further recommended, because it is convenient and causes less secondary pollution (Cheng et al., 2015). Many studies have used adsorption methods to remove $\mathrm{BaP}$ from different edible vegetable oils and fats by adsorption, such as fish oil (Yebra-Pimentel et al., 2014), sesame oil (Choi et al., 2014), olive pomace oil (Kiralan \& Tekin, 2020) and so on. Commonly used adsorbents are activated carbon and activated clay applied to the adsorption of $\mathrm{BaP}$ in edible oil (Choi et al., 2014). However, because of the insufficient supply of these commercial adsorbents for the removal of $\mathrm{BaP}$, the development of other adsorbents has attracted great attention.

It is worth noting that biochar has been extensively used as an adsorbent for adsorbing heavy metals, dyes, and organic contaminants, particularly aromatics in recent years (Ahmed \& Hameed, 2018; Lin et al., 2020). Biochar could be prepared from a variety of raw materials, such as activated sludge, 
agricultural waste and animal manure, of which sesame straw could be viewed as an excellent alternative duo to its inherently renewable characteristics, low toxicity, and wide availability (Park et al., 2016). Cellulose, hemicellulose, and lignin are the three basic components of these waste lignocellulosic biomass resources, whose intrinsic structures are different from each other (Deng et al., 2016). Cellulose is consisted of long-chain polysaccharides without branches, while hemicellulose is a highly branched macromolecular substance of different sugars and has a random and amorphous structure. Lignin is a complex cross-linked polymer composed of phenylpropanoid units (Smith et al., 2017). Because of their different intrinsic structures and pyrolysis behaviors, these constituents produce biochars with different properties. To date, numerous studies have illustrated the physical and chemical properties of biochars prepared from cellulose, hemicellulose, and lignin, and their capacities for adsorbing toxic pollutants in water (Li et al., 2014; Wan et al., 2020; Yang et al., 2018). However, biochars from these three key biomass constituents have not been used for the removal of organic pollutants, especially $\mathrm{BaP}$, from edible oil.

In this work, we extracted cellulose, hemicellulose, and lignin from sesame straw, and used them to prepare biochars. The structures and surface properties of both unmodified biochars and biochars modified with the activator $\mathrm{ZnCl}_{2}$ were investigated. Sorption kinetics and isotherms of $\mathrm{BaP}$ on the biochar were investigated to understand the removal process, mechanism, and capacity. This work provides the experimental basis for the development of new adsorbents for the removal of $\mathrm{BaP}$ in edible oil, and for the transformation of sesame straw from waste into a valuable resource.

\section{Materials and methods}

\subsection{Materials}

Sesame straw was obtained from a farm in Zhumadian, China. It was milled with an electric grinder and sieved through a 40 -mesh sieve. The resulting powder was dewaxed using a toluene-ethanol solution $(2: 1, \mathrm{v} / \mathrm{v})$ in a Soxhlet extractor for $48 \mathrm{~h}$, and then air-dried. All chemicals used in all experiments were of analytical grade.

\subsection{Isolation of cellulose}

Cellulose was isolated from the dewaxed samples according to the previous method with some modifications (Liu et al., 2020) Dewaxed samples were treated with $1.25 \mathrm{M} \mathrm{NaOH}$ solution for $6 \mathrm{~h}$ at $60^{\circ} \mathrm{C}$ (solid:liquid ratio, 1:20) under constant stirring. After treatment with $\mathrm{NaOH}$ solution, the fibers extracted were thoroughly washed with distilled water to ensure the $\mathrm{pH}$ of the fibers was neutral. Then, the neutral $\mathrm{pH}$ fibers were immersed in $10 \%$ acetic acid solution for $30 \mathrm{~min}$, rinsed, filtered, then oven-dried. The dried fibers were bleached using $7 \%$ sodium chlorite at $80^{\circ} \mathrm{C}$ for $2 \mathrm{~h}$. The ratio of fiber to sodium chlorite was maintained at 1:10. Then, the bleached fibers were washed three times with distilled water. Lastly, the fibers were immersed in $5 \%$ acetic acid to neutralize the alkali, washed with distilled water, and then freeze-dried.

\subsection{Isolation of hemicellulose and lignin}

Hemicellulose and lignin were isolated from the dewaxed samples according to the previous report (Banerjee et al., 2019). Dewaxed samples were mixed with $1.25 \mathrm{M} \mathrm{NaOH}$ solution and stirred at $60^{\circ} \mathrm{C}$ for $6 \mathrm{~h}$ (solid:liquid, 1:20) under constant stirring. The collected supernatant was adjusted to $\mathrm{pH}$ 5.5-6 with $6 \mathrm{M} \mathrm{HCl}$, and concentrated by rotary evaporators. Then it was precipitated in three volumes of $95 \%$ ethanol for $24 \mathrm{~h}$, and centrifuged to isolate hemicellulose. After that, the precipitate (hemicellulose) was dialyzed at $25^{\circ} \mathrm{C}$ for $72 \mathrm{~h}$ by reverse flow to remove $\mathrm{NaCl}$, and finally freeze-dried. After the removal of hemicellulose, the supernatant solution was evaporated to remove ethanol. After ethanol evaporation, $6 \mathrm{M} \mathrm{HCl}$ was added to the supernatant, which was then acidified to $\mathrm{pH} 2.0$ to precipitate lignin. The precipitated lignin was washed with deionized water to remove residual impurities, and finally freeze-dried.

\subsection{Biochar preparation}

The cellulose, hemicellulose, lignin and sesame straw were thoroughly mixed with $\mathrm{ZnCl}_{2}$ at 1:2 (w/w). $20 \mathrm{~g}$ of each dried sample was added to a quartz boat and placed in a tubular furnace (OTF-1200X, Hefei Kejing Material Technology Co., Ltd) filled with nitrogen gas. After that, the furnace was programmed to increase in temperature at a rate of $10^{\circ} \mathrm{C} / \mathrm{min}$ from room temperature to pyrolysis temperatures of $600^{\circ} \mathrm{C}$, hold for $1 \mathrm{~h}$, and then cool to room temperature. During the heat treatment, a flow of pure nitrogen (99.999\%) was maintained at $300 \mathrm{~mL} / \mathrm{min}$ (Ma et al., 2019). Biochars obtained from cellulose, hemicellulose, lignin and sesame straw without $\mathrm{ZnCl}_{2}$ activation, representing unmodified biochars, were named CC, HC, LC, and SC, respectively; while those with $\mathrm{ZnCl}_{2}$ activation, representing modified biochars, were named CZC, HZC, LZC, and SZC, respectively.

\subsection{Characterizations of biochars}

To investigate the composition of the biochars, carbon, oxygen, nitrogen, hydrogen and sulfur contents of the samples were determined using an elemental analyzer (Elementar Unicube, Germany). Chemically active groups on the biochar surfaces were identified by a Nicolet 6700 Fourier transform infrared spectroscopy (FT-IR) with a spectrometer (Thermo Fisher Scientific, USA) in the scanning range of $4000-400 \mathrm{~cm}^{-1}$ (Ahmed \& Hameed, 2018). The surface morphologies were observed with a scanning electron microscope (Hitachi, S-3000N). The samples were placed on the tape and sprayed with gold, then observed and photographed (Choudhary et al., 2020). The crystallographic structures were measured by an $\mathrm{X}$-ray diffractometer at a scanning rate of $10 \% \mathrm{~min}$ over a $2 \theta$ range from 10 to $80^{\circ}$ (Ma et al., 2019). For thermogravimetric analysis, an SDT Q600 thermogravimeter (TA Instruments, New Castle, DE, USA) was used. Each biochar sample was heated from 40 to $800{ }^{\circ} \mathrm{C}$ at a heating rate of $10^{\circ} \mathrm{C} / \mathrm{min}$ in an $\mathrm{N}_{2}$ atmosphere (Choudhary et al., 2020). The porosity of the biochars was determined by $\mathrm{N}_{2}$ adsorption at $-196{ }^{\circ} \mathrm{C}$ with a porosimeter and an automated surface area analyzer (Ahmed \& Hameed, 2018). 


\subsection{Removal of BaP from sesame oil}

The removal of $\mathrm{BaP}$ from sesame oil by biochar was carried out according to the method described by Shi et al. (2017). First, sesame oils were contaminated with $\mathrm{BaP}$ at $18 \mu \mathrm{g} / \mathrm{kg}$, and then stored for $48 \mathrm{~h}$. The proportion of biochars to be used as adsorbent was set at $0.6 \%$ of the oil by weight. $50 \mathrm{~g}$ of the sesame oil and $0.3 \mathrm{~g}$ of the biochar were combined in a three-neck flask, stirred at $110{ }^{\circ} \mathrm{C}$ for 35 min under vacuum, and then filtered to remove biochar.

\subsection{Determination of BaP in sesame oil}

The same procedure was carried out with samples of sesame oils taken before and after adsorption. $0.5 \mathrm{~g}$ of oil was weighed, combined with $3 \mathrm{~mL} n$-hexane into $10 \mathrm{~mL}$ centrifuge tubes, and then whirled for $1 \mathrm{~min}$. Subsequently, the solution was loaded on a column (CNW MIP-BAP catridge, $500 \mathrm{mg}, 6 \mathrm{~mL}$ ) which had been activated with $5 \mathrm{~mL}$ dichloromethane and $10 \mathrm{~mL} n$-hexane. After loading, the column was eluted with $10 \mathrm{~mL} n$-hexane. The extracts adsorbed onto the column were eluted by $5 \mathrm{~mL}$ of dichloromethane, and the total elution was collected. The eluent was then concentrated to dryness with nitrogen at $45^{\circ} \mathrm{C}$. The residue was dissolved in $1 \mathrm{~mL}$ of acetonitrile. Next, the final solution was filtered through a $0.22 \mu \mathrm{m}$ organic membrane, and then collected for HPLC analysis (Pan et al., 2017).

The BaP content was determined by an HPLC (Agilent 1200, USA) system equipped with an FLD detector and a $\mathrm{PAH} \mathrm{C}_{18}(250 \mathrm{~mm} \times 4.6 \mathrm{~mm} \times 5 \mu \mathrm{m})$ chromatographic column. The mobile phase consisted of acetonitrile (solvent A) and water (solvent B). The flow rate of solvent was $1.0 \mathrm{~mL} / \mathrm{min}$ for $35 \mathrm{~min}$, and the gradient was as follows: $0 \mathrm{~min}, 60 \% \mathrm{~A} ; 0-8 \mathrm{~min}, 60 \% \mathrm{~A}$; 8-18 min, 60-100\% A; 18-28 min, 100\% A; 28-29 min, 100-60\% A; $29-35 \mathrm{~min}, 60 \% \mathrm{~A}$. The injection volume of the prepared sample was $10 \mu \mathrm{L}$, and the column temperature was kept at $35^{\circ} \mathrm{C}$ during injection. BaP, which appeared at $22.439 \mathrm{~min}$, was identified by comparing the retention time of the peak with that of the $\mathrm{BaP}$ standard. BaP was quantified based on the external standard curve at concentrations ranging from $0.04-50.00 \mathrm{ng} / \mathrm{g}$. The coefficient of correlation $\left(\mathrm{R}^{2}\right)$ of the standard curve was 0.9998 .

The removal efficiency $(\gamma)$ of BaP was calculated by the mass balance Equation 1:

$\gamma=\left(\frac{C_{0}-C_{t}}{C_{0}}\right) \times 100 \%$

where $C_{0}(\mu \mathrm{g} / \mathrm{kg})$ and $C_{t}(\mu \mathrm{g} / \mathrm{kg})$ are the concentrations of $\mathrm{BaP}$ at the initial and given times (min), respectively.

The amount of BaP adsorbed at equilibrium, $\mathrm{q}_{\mathrm{e}}(\mu \mathrm{g} / \mathrm{kg})$, was calculated according to Equation 2:

$q_{e}=\frac{\left(C_{o}-C_{e}\right) \rho V}{W}$

in which, $\rho(\mathrm{g} / \mathrm{L})$ represents the density of the sesame oil; $C_{e}$ $(\mu \mathrm{g} / \mathrm{kg})$ is the equilibrium concentration of $\mathrm{BaP} ; \mathrm{V}(\mathrm{L})$ is the volume of contaminated sesame oil, and $\mathrm{W}$ is the weight of biochar used.

\subsection{Adsorption behavior of biochar}

Langmuir and Freundlich isotherm adsorption models were applied to study the equilibrium adsorption data (Amaral et al., 2018). The Langmuir isotherm equation is expressed in Equation 3:

$\frac{C_{e}}{q_{e}}=\frac{C_{e}}{q_{m}}+\frac{1}{b \times q_{m}}$

where, $\mathrm{q}_{\mathrm{e}}$ is the amount of $\mathrm{BaP}$ sorbed in $\mu \mathrm{g} / \mathrm{kg}$ at equilibrium, $\mathrm{b}(\mu \mathrm{g} / \mathrm{kg})$ is the Langmuir isotherm constant corresponding to the energy of sorption, and $\mathrm{q}_{\mathrm{m}}(\mu \mathrm{g} / \mathrm{kg})$ is the biochar's maximum capacity for adsorbing $\mathrm{BaP}$.

The linear form of the Freundlich isotherm is given in Equation 4:

$\ln q_{e}=\ln K_{f}+\frac{1}{n} \ln C_{e}$

where, $K_{f}$ and $n$ are Freundlich constants, $K_{f}(\mu g / k g)$ is the adsorption capacity of the biochar, and $\mathrm{n}$ is an indicator of adsorption intensity.

The kinetics of adsorption of $\mathrm{BaP}$ on biochars were studied by applying the pseudo-first-order model and the pseudosecond-order model (Guo et al., 2020). The best fitting model of the dynamic adsorption rate and the adsorption mechanism of the $\mathrm{BaP}$ in the contaminated oils were determined from Equations 5 and 6:

$$
\begin{aligned}
& \ln \frac{q_{e-} q_{t}}{q_{e}}=-k_{1} t \\
& \frac{t}{q_{t}}=\frac{1}{k_{2} q_{e}^{2}}+\frac{t}{q_{e}}
\end{aligned}
$$

where $\mathrm{q}_{\mathrm{t}}(\mu \mathrm{g} / \mathrm{kg})$ is the adsorption efficiency of $\mathrm{BaP}$ by the biochar at time $\mathrm{t}(\mathrm{min}), \mathrm{k}_{1}(1 / \mathrm{min})$ is the first-order rate constant, and and $\mathrm{k}_{2}[\mathrm{~kg} /(\mu \mathrm{g} \cdot \mathrm{min})]$ is the second-order rate constant. The first-order rate constant is calculated according to the intercept of $\ln \left(\mathrm{q}_{\mathrm{e}}-\mathrm{q}_{\mathrm{t}}\right)$ against $\mathrm{t}$, while the second-order rate constant is calculated according to the slope of $\left(\mathrm{t} / \mathrm{q}_{\mathrm{t}}\right)$ against $\mathrm{t}$.

The thermodynamic parameters can be calculated using the following Equations 7 to 10:

$$
\begin{aligned}
& \Delta G^{0}=-R T \ln K_{d} \\
& K_{d}=\frac{q_{e}}{C_{e}} \\
& \Delta G^{0}=\Delta H^{0}-T \Delta S^{0} \\
& \ln K_{d}=\frac{\Delta S^{0}}{R}-\frac{\Delta H^{0}}{R T}
\end{aligned}
$$

where $\Delta G^{0}(\mathrm{~J} / \mathrm{mol})$ is the standard Gibbs free energy change, $\mathrm{K}_{\mathrm{d}}$ is the distribution coefficient of the adsorption process, $\mathrm{T}(\mathrm{K})$ is the adsorption temperature in ${ }^{\circ} \mathrm{Kelvin}, \mathrm{R}[8.314 \mathrm{~J} /(\mathrm{mol} \cdot \mathrm{K})]$ is the universal gas constant, $\Delta \mathrm{S}^{0}$ is entropy, and $\Delta \mathrm{H}^{0}$ is enthalpy. The values of $\Delta \mathrm{S}^{0}$ and $\Delta \mathrm{H}^{0}$ can be determined using the curve intercept and slope of $\ln \mathrm{K}_{\mathrm{d}}$ versus $1 / \mathrm{T}$, respectively. 


\subsection{Statistical analysis}

All experiments were performed three times, and the results are presented as mean \pm standard deviation (SD). An analysis of variance (ANOVA) was performed using SPSS (version 20.0; SPSS Inc., Chicago, USA) and Duncan's multiple comparison test was used to evaluate whether differences $(\mathrm{p}<0.05)$ between samples were significant.

\section{Results and discussion}

\subsection{Biochar yield and composition}

The yields of the unmodified and modified biochars are shown in Figure 1A. It is noteworthy that the yield of LC was much higher $(24.98 \%)$ than that of CC (16.42\%) and HC $(20.56 \%)$ at $600^{\circ} \mathrm{C}$. Lignin is a three-dimensional, highly cross-

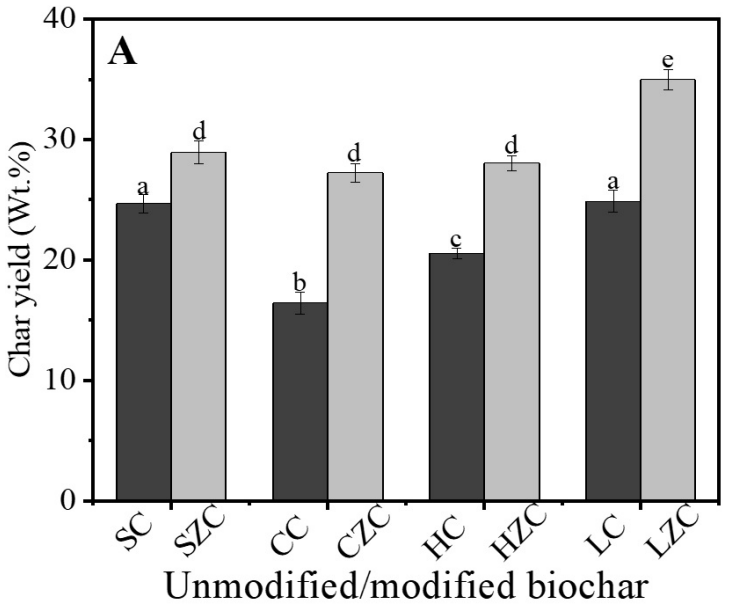

linked, macromolecular polymer with a thermal degradation temperature in the range of $100-800^{\circ} \mathrm{C}$. In contrast, the thermal degradation temperatures of hemicellulose and cellulose are mainly in the range of $100-400{ }^{\circ} \mathrm{C}$ (Ma et al., 2015; Yang et al., 2007). Therefore, the highest thermal stability of lignin might result in the highest yield of $\mathrm{LC}$ at high pyrolysis temperature. After activation, the yields of SZC, CZC, HZC, and LZC increased by $28.92 \%, 27.23 \%, 28.04 \%, 37.98 \%$ and $48.3 \%$, respectively. In other words, the addition of $\mathrm{ZnCl}_{2}$ increased the yields of all biochars. This is because $\mathrm{ZnCl}_{2}$ favors depolymerization, dehydration, and redistribution of the biopolymers, and also promotes the conversion of aliphatic to aromatic compounds; all of these transformations increase, the yield of biochar (Pezoti et al., 2014).

The elemental composition and molar ratios of the biochars are listed in Table 1. Hydrogen content was similar

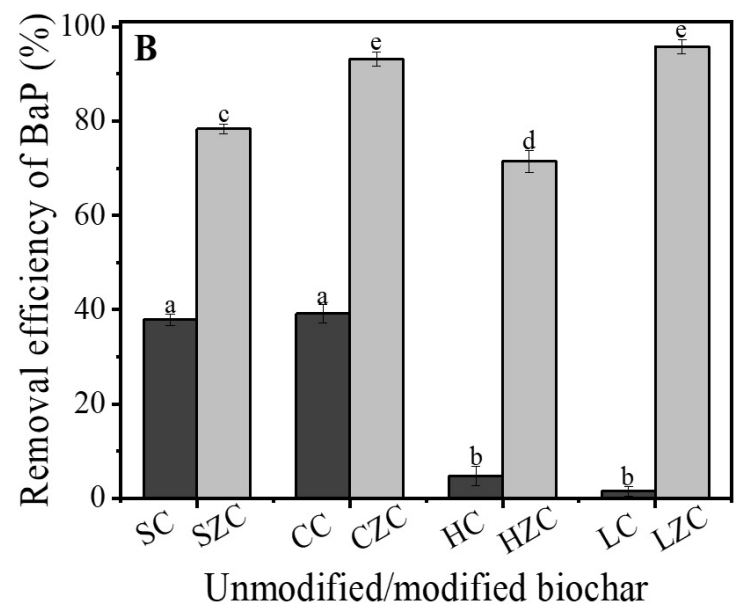

Figure 1. Biochar Yields (A); Efficiency of different biochars in removing BaP from oil (B). Results with different letters are significantly different $(\mathrm{p}<0.05)$.

Table 1. Physicochemical properties of biochars.

\begin{tabular}{|c|c|c|c|c|c|c|c|c|}
\hline & \multicolumn{8}{|c|}{ Sample } \\
\hline & $\mathrm{SC}$ & $\mathrm{CC}$ & $\mathrm{HC}$ & $\mathrm{LC}$ & $\mathrm{SZC}$ & $\mathrm{CZC}$ & $\mathrm{HZC}$ & LZC \\
\hline \multicolumn{9}{|c|}{ Elemental copositions } \\
\hline $\mathrm{N}(\%)$ & 1.96 & 0.03 & 2.38 & 6.07 & 2.99 & 0.80 & 2.67 & 4.69 \\
\hline $\mathrm{C}(\%)$ & 77.15 & 76.87 & 64.98 & 83.14 & 86.83 & 89.96 & 87.40 & 82.78 \\
\hline $\mathrm{H}(\%)$ & 2.10 & 2.26 & 2.41 & 2.34 & 1.74 & 1.77 & 1.87 & 2.18 \\
\hline $\mathrm{S}(\%)$ & 0.51 & 0.24 & 0.82 & 0.20 & 0.21 & 0.00 & 0.41 & 0.20 \\
\hline $\mathrm{O}(\%)$ & 10.30 & 2.65 & 12.72 & 3.39 & 2.23 & 1.10 & 2.31 & 4.60 \\
\hline $\mathrm{H} / \mathrm{C}$ & 0.0272 & 0.0294 & 0.0371 & 0.0281 & 0.0200 & 0.0197 & 0.0214 & 0.0263 \\
\hline $\mathrm{O} / \mathrm{C}$ & 0.1335 & 0.0345 & 0.1958 & 0.0408 & 0.0257 & 0.0122 & 0.0264 & 0.0556 \\
\hline \multicolumn{9}{|c|}{ Pore structure $^{\mathrm{a}}$} \\
\hline $\mathrm{S}_{\mathrm{BET}}\left(\mathrm{m}^{2} / \mathrm{g}\right)$ & 133.01 & 387.83 & 29.14 & 16.78 & 1496.82 & 1915.55 & 1362.72 & 983.50 \\
\hline $\mathrm{V}_{\text {tot }}\left(\mathrm{cm}^{3} / \mathrm{g}\right)$ & 0.1060 & 0.2145 & 0.0343 & 0.0171 & 1.0355 & 1.1854 & 1.1390 & 0.7272 \\
\hline $\mathrm{V}_{\text {micro }}\left(\mathrm{cm}^{3} / \mathrm{g}\right)$ & 0.0204 & 0.1443 & 0.0052 & 0.0006 & 0.5543 & 0.9815 & 0.2482 & 0.3937 \\
\hline $\mathrm{V}_{\text {meso }}\left(\mathrm{cm}^{3} / \mathrm{g}\right)$ & 0.0856 & 0.0702 & 0.0290 & 0.0164 & 0.4812 & 0.2039 & 0.8908 & 0.3335 \\
\hline $\mathrm{V}_{\text {micro }}(\%)$ & 19.25 & 67.27 & 15.16 & 3.51 & 53.53 & 82.80 & 21.79 & 54.14 \\
\hline $\mathrm{A}_{\mathrm{m}}(\mathrm{nm})$ & 3.19 & 2.21 & 4.70 & 4.07 & 2.77 & 2.48 & 3.34 & 2.96 \\
\hline
\end{tabular}

${ }^{a} \mathrm{~S}_{\mathrm{BET}}-\mathrm{BET}$ specific surface area; $\mathrm{V}_{\text {tot }}-$ Total pore volume; $\mathrm{V}_{\text {micro }}$-Micropore volume; $\mathrm{V}_{\text {meso }}$-Mesopore volume; $\mathrm{V}_{\text {micro }}-$ Microporous volume ratio; $\mathrm{A}_{\mathrm{m}}-$ Average pore diameter. 
in all the biochars; however, the percentage of carbon was considerably increased after activation. The significant loss in oxygen in the modified biochars can be attributed to the cracking and cleavage of weak bonds within the precursor materials (Liu et al., 2021). The $\mathrm{H} / \mathrm{C}$ ratios, an index of carbon aromaticity, of the modified biochars were slightly lower than those of the unmodified biochars. The result signifies that $\mathrm{ZnCl}_{2}$ activation enhanced the carbon aromaticity of the biochars. The $\mathrm{O} / \mathrm{C}$ ratios of the SZC, CZC and HZC were lower than those of unmodified biochars. And the high $\mathrm{O} / \mathrm{C}$ of unmodified biochar SC, CC, and HC indicated a low carbonization degree and the existence of polar functional groups. However, the opposite result, i.e., the low $\mathrm{O} / \mathrm{C}$ of LZC, indicated that LZC had a richer polar functional group (Li et al., 2020; Liu et al., 2018).

\subsection{FT-IR analysis}

Figure 2A shows the FT-IR spectra of unmodified and modified biochars derived from sesame straw, cellulose, hemicellulose, and lignin; peaks have been identified according to the literature (Pezoti et al., 2014; Li et al., 2020). The absorbance peaks at $3345 \mathrm{~cm}^{-1}, 1732 \mathrm{~cm}^{-1}, 1116 \mathrm{~cm}^{-1}$ were assigned to stretching vibration of $-\mathrm{OH}, \mathrm{C}=\mathrm{O}$ and $\mathrm{C}-\mathrm{O}-\mathrm{C}$, respectively. The vibration peaks at $2965 \mathrm{~cm}^{-1}$ and $2927 \mathrm{~cm}^{-1}$ corresponded to the $\mathrm{C}-\mathrm{H}$ bonds from alkyl groups. The band from $1580 \mathrm{~cm}^{-1}$ to $1664 \mathrm{~cm}^{-1}$ can be attributed to the $\mathrm{C}=\mathrm{C}$ vibration of an aromatic ring (Hong et al., 2019). The signal intensity of $\mathrm{C}=\mathrm{C}$ groups, for LZC was clearly enhanced, indicating increased aromatization and stability. Meanwhile, the presence of $\mathrm{C}=\mathrm{C}$ double bonds in aromatic rings could enhance the adsorptive capacity of biochars, favoring the $\pi-\pi$ interactions that are one of the main mechanisms for the adsorption of aromatic pollutants. Comparing SZC with SC, the most obvious difference was the functional group - $\mathrm{OH}$, which almost disappears in SZC; this was in accordance with the above results of sharp decrease of $\mathrm{H}$ (see Table 1). Moreover, comparing CZC with CC, the peaks strength obviously decreased in the former due to $\mathrm{ZnCl}_{2}$ activation. No obvious difference was observed between HC and HZC. However, comparing with LC, the peak strength of LZC increased significantly. The existence of adsorption bands in the spectra for biochars signified that biomasses were not completely decomposed. The maintenance of functional groups in biochars can improve the performance of biochars, because these functional groups may provide active sites for adsorption.

\subsection{XRD analysis}

As depicted in Figure 2B, the XRD patterns exhibited two diffraction peaks at $24^{\circ}$ and $43^{\circ}$, which corresponded to amorphous, disordered carbon material. Comparing with the unmodified biochars, the crystal planes of (002) and (100) on the modified biochars were enhanced; this clearly indicates increasing regularity of the layered structure, leading to a layered arrangement due to the short range of the crystallographic structure of the carbon network (Danish et al., 2014). Interestingly, the peaks related to cellulose shifted up to $2 \theta=25^{\circ}$ after activation. This might result from inter- or intra-molecular crosslinking of polymeric chains, leading to the formation of aromatic hydrocarbons (Lee et al., 2019). Over-all, $\mathrm{ZnCl}_{2}$ activation enhanced aromaticity and the formation of more orderly graphitic structures at the pyrolysis temperature of $600^{\circ} \mathrm{C}$. The graphene-shaped atomic structure may be an important reason for the stability of biochars at high temperatures $\left(\geq 600^{\circ} \mathrm{C}\right)$ (Wu et al., 2012).
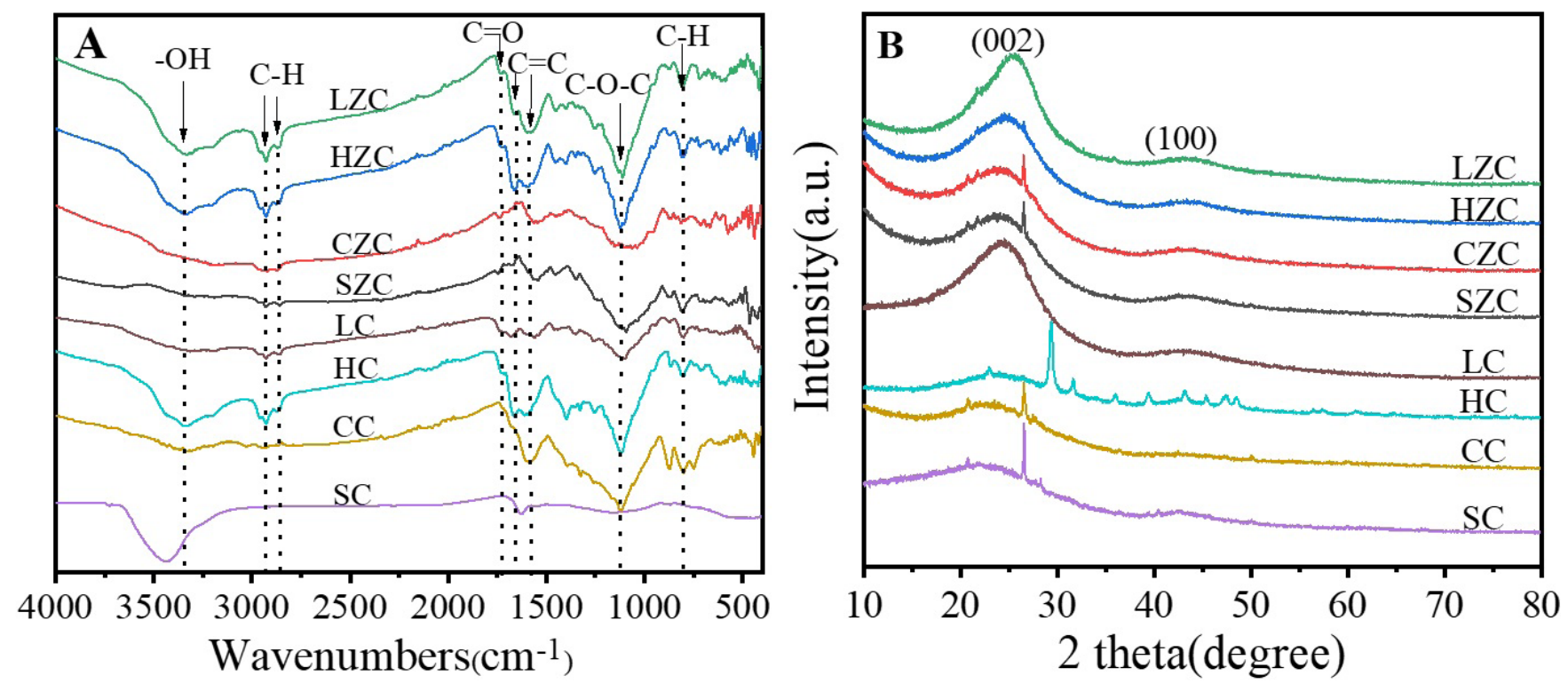

Figure 2. FT-IR spectra of unmodified and modified biochars (A); XRD patterns of unmodified biochars (SC, CC, HC and LC) and modified biochars (SZC, CZC, HZC, and LZC) (B). 


\subsection{Surface morphology}

Significant changes were observed in comparing the surface topographies of unmodified and modified biochars. As can be seen in Figure 3, unmodified and modified biochars appeared dehydrated and decomposed at $600{ }^{\circ} \mathrm{C}$. They had no porous structure, resulting in low surface areas. The micromorphology of modified biochar obtained with the same activator $\left(\mathrm{ZnCl}_{2}\right)$ was different in this study. The surface of modified biochars SZC and CZC showed more cavities, with pores of different sizes and shapes. According to the SEM images (Figure 3B and Figure 3D), it seemed that the cavities resulted from the evaporation of $\mathrm{ZnCl}_{2}$, leaving the space previously occupied by the reagents (Deng et al., 2009). The biochar from hemicellulose (Figure 3E) showed a laminar structure and textured surface with "bubbles" that had formed during pyrolysis. Compared with SZC, CZC and HZC, LZC was the loosest and the most porous. These highly developed pores make LZC a promising adsorbent for industrial applications.
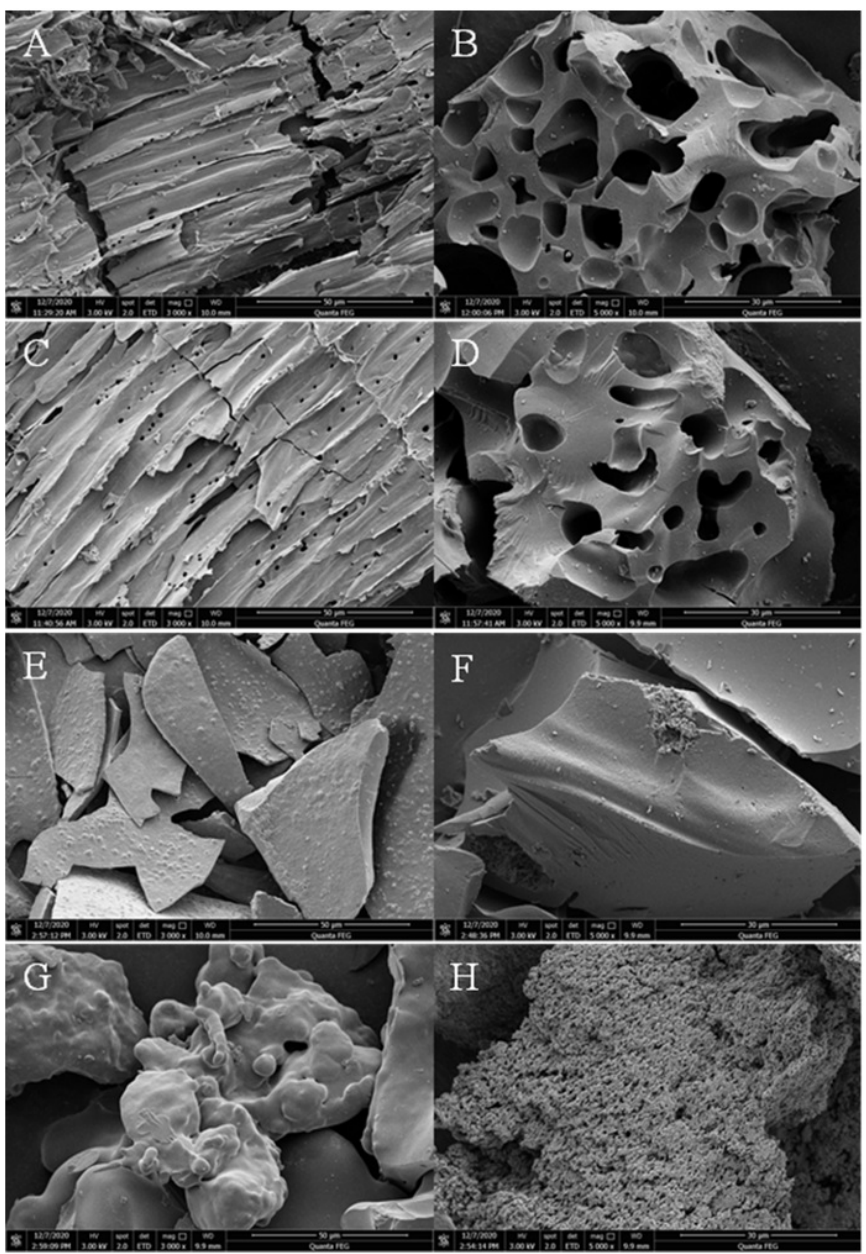

Figure 3. SEM images of unmodified and modified biochars produced from sesame straw, cellulose, hemicellulose and lignin by $\mathrm{ZnCl}_{2}$ activation at $600{ }^{\circ} \mathrm{C}$ : (A) SC; (B) SZC; (C) CC; (D) CZC; (E) HC; (F) HZC; (G) LC; (H) LZC.

\subsection{Thermogravimetric analysis (TGA)}

As shown in Figure 4, there were obvious differences in TGA and derivative thermogravimetric curves (DTG) of unmodified and modified biochars, illustrating the effect of $\mathrm{ZnCl}_{2}$ addition on biochar stability. The degradation of biochars was slow until high temperatures were reached, indicating strong thermal stability. The curves for all biochars showed the loss of water up to $140{ }^{\circ} \mathrm{C}$. The existence of water in the biochars can be explained by their hygroscopicity (Jesus et al., 2019). The subsequent loss up to $800{ }^{\circ} \mathrm{C}$ was related to the decomposition of cellulose, hemicellulose, and lignin. Compared to other unmodified biochars, CC experienced a noticeable mass loss between $300^{\circ} \mathrm{C}$ and $600{ }^{\circ} \mathrm{C}$, demonstrating that it still contained plentiful volatile and thermolabile substances. Lower mass loss means higher thermal stability. Compared to SC, CC and HC, the TGA curves of SZC, CZC, and HZC pulled back with the increase of temperature, indicating that $\mathrm{ZnCl}_{2}$ addition improved the thermal stability of the biochars.

The DTG of all biochars illustrated mass loss rates in detail. From these curves, temperature periods can be identified, marking periods of significant mass loss. All biochar samples achieved maximum mass loss rate in the temperature range of $640-750{ }^{\circ} \mathrm{C}$. The temperatures corresponding to the maximum rates of weight loss of modified biochars from cellulose, hemicellulose and sesame straw were higher than those of unmodified biochar. In addition, the values of maximum rates of weight loss at peaks were smaller. There was no significant difference in weight loss between LC and LZC, perhaps because the weight loss rate of lignin was the same. This was consistent with the previous research results of Li et al. (2020).

\subsection{Nitrogen adsorption assays}

The textural properties of the unmodified/modified biochars were expressed by the nitrogen adsorption/desorption isotherm at $-196{ }^{\circ} \mathrm{C}$ (Figure 5). Figure 5A shows that the unmodified biochars had I-type isotherms, which indicated these samples were essentially microporous solids. Figure 5B clearly shows hysteresis loops in the adsorption/desorption isotherms of the modified biochars, indicating that they were intermediate between type I and IV isotherms, and reflecting the predominance of micropores and mesopores in the modified biochars. The hysteresis loop at the relative pressures ranges between 0.4 and 1.0 evidenced mesopore presence (Brazil et al., 2020), while the steep rise in adsorption in the range of 0-0.05 indicated the existence of micropores. This result is consistent with the SEM observations. The isotherms of SC, CC, and HC did not close at low pressure, which may be due to capillary condensation.

The BET surface areas, and characteristics of pore size and pore volumes of the biochars are given in Table 1 . The results show that the unmodified and modified biochar samples have different textures. The biochars that adsorbed more nitrogen exhibited a larger specific surface area. $\mathrm{ZnCl}_{2}$ activation significantly improved the BET specific surface area, as the surface area 

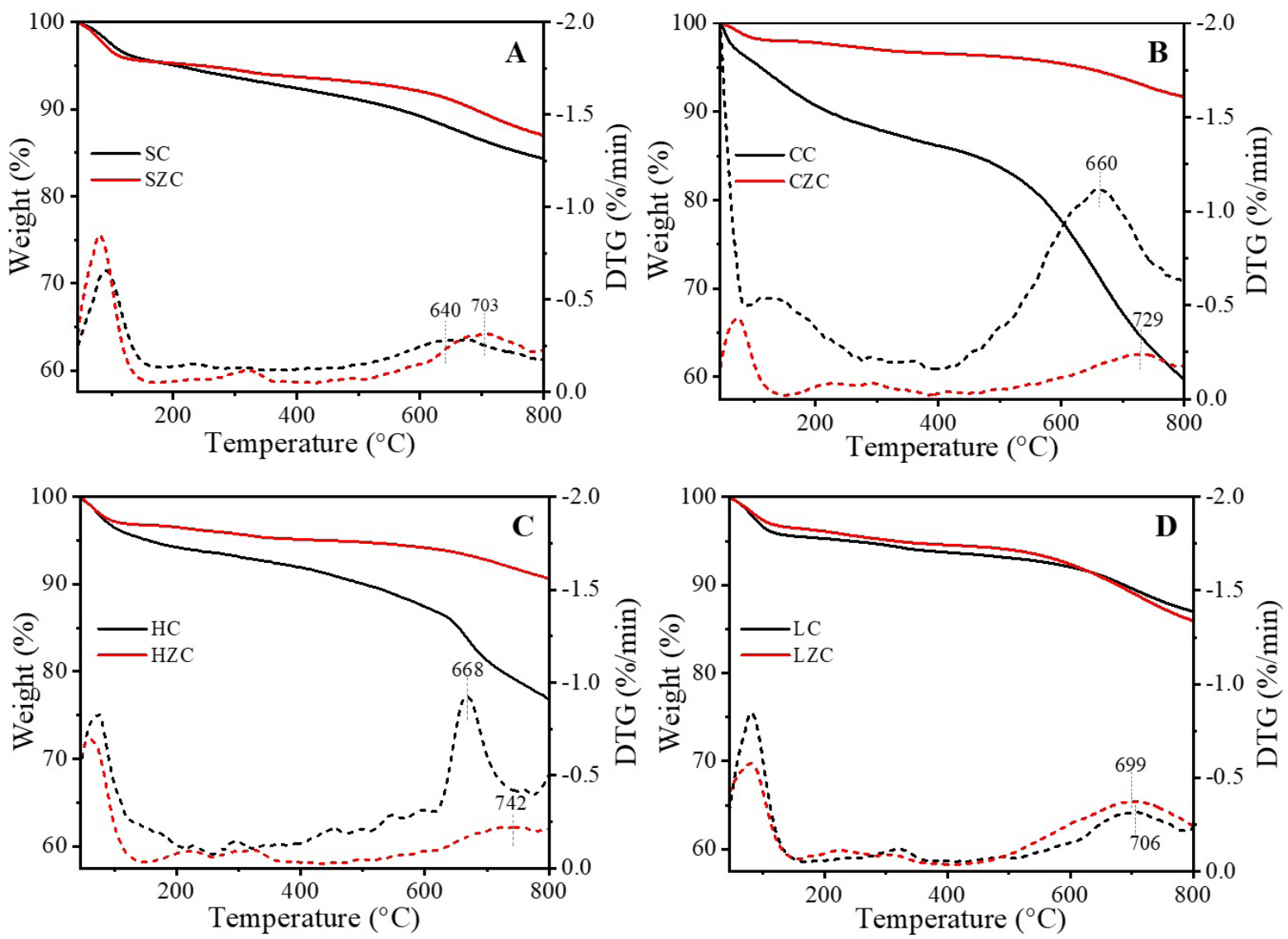

Figure 4. Thermogravimetric analysis of unmodified biochar and modified biochar (A, sesame straw-based biochar; B, cellulose-based biochar; C, hemicellulose-based biochar; D, lignin-based biochar).
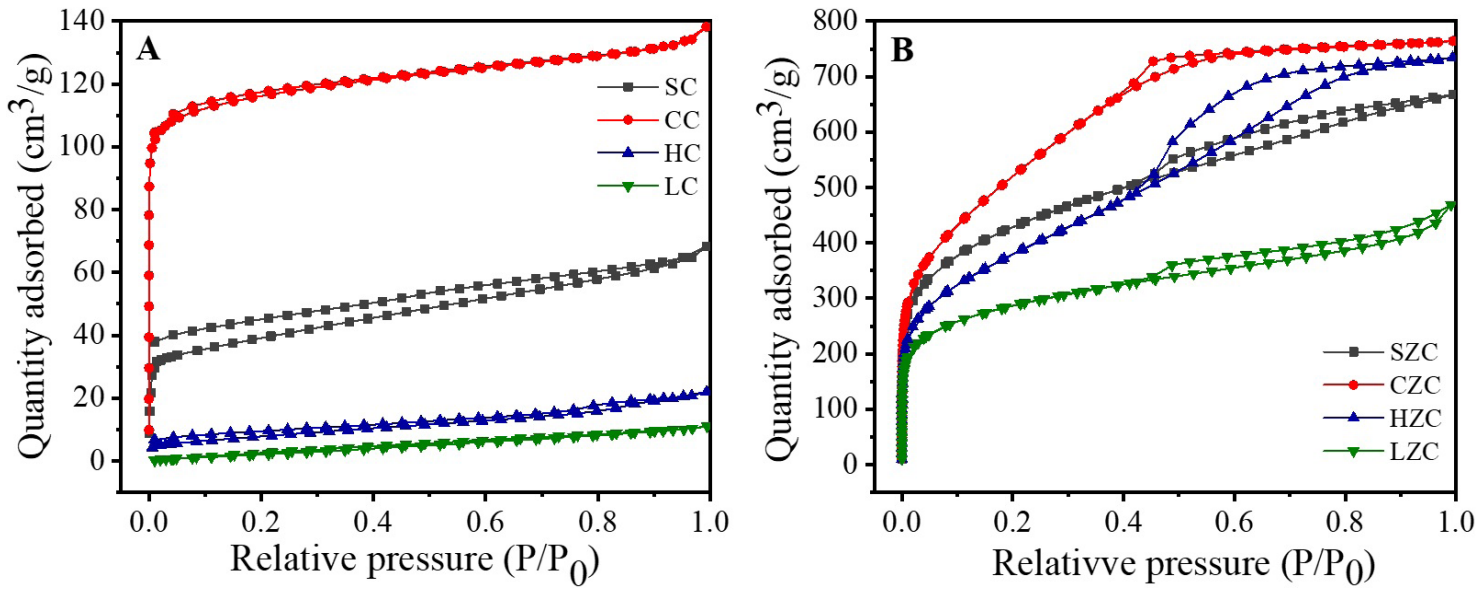

Figure 5. Nitrogen adsorption isotherms of the unmodified and modified biochars (A, unmodified biochars; B, modified biochars).

increased from $16.78-133.01 \mathrm{~m}^{2} / \mathrm{g}$ for unmodified biochars to $983.50-1915.55 \mathrm{~m}^{2} / \mathrm{g}$ for modified biochars. The highest surface area was $1915.55 \mathrm{~m}^{2} / \mathrm{g}$ for the modified biochar (CZC) produced from cellulose. It has been reported that $\mathrm{ZnCl}_{2}$ destroys the lateral bonds in cellulose molecules, resulting in the formation of activated carbon with a higher surface area (Molina-Sabio \& Rodríguez-Reinoso, 2004). The micropore volumes of the unmodified biochars SC, CC, HC, and LC were $0.0204 \mathrm{~cm}^{3} / \mathrm{g}$,
$01443 \mathrm{~cm}^{3} / \mathrm{g}, 0.0052 \mathrm{~cm}^{3} / \mathrm{g}, 0.0006 \mathrm{~cm}^{3} / \mathrm{g}$, respectively. Compared with the volume of unmodified biochars, LZC (656.17 times) had the largest increase in the volume of modified biochars. It was concluded that the activating agent $\mathrm{ZnCl}_{2}$ promoted the development of a porous structure of biochar during pyrolysis. The prepared modified biochars with well-developed pore structure and large specific surface area are expected to fully adsorb $\mathrm{BaP}$ in oil through a pore-filling mechanism. 


\subsection{BaP removal experiment}

\section{Adsorption of $\mathrm{BaP}$}

The $\mathrm{BaP}$ removal percentages achieved by using the different biochars are displayed in Figure 1B. The data revealed the superior performance of modified biochars, compared to unmodified biochars, with values in the ranges 71.41-95.79\% and $1.47-39.15 \%$, respectively. It should be noted that the $\mathrm{BaP}$ removal percentage obtained by unmodified LC was only $1.47 \%$, whereas that by biochar modified with $\mathrm{ZnCl}_{2}$ (i.e., LZC) was $95.79 \%$. It has been reported that the surface area of biochar directly influences its adsorptive capacity (Oliveira et al., 2020). LZC has the smallest surface area among the modified biochars, but it has the greatest adsorption capacity. This result indicated that the adsorption capacity of biochars is related to other factors as well as surface area. According to Jesus et al. (2017), a higher aromaticity index of biochars and their precursor biomasses leads to greater removal of PAH from aqueous media.

The following assays were performed using the LZC adsorbent, because the higher adsorption efficiency of LZC indicated that it was the best candidate to be used as an industrial adsorbent of $\mathrm{BaP}$.

\section{$\mathrm{BaP}$ adsorption kinetics and thermodynamics}

Effect of contact time on the amount of $\mathrm{BaP}$ adsorbed onto LZC was assessed from 1 to $50 \mathrm{~min}$ at three initial $\mathrm{BaP}$ concentrations $(\sim 8.95 \mu \mathrm{g} / \mathrm{kg}, 18.99 \mu \mathrm{g} / \mathrm{kg}$ and $27.29 \mu \mathrm{g} / \mathrm{kg})$. As shown in Figure $6 \mathrm{~A}$, when contact time increased, the amounts of $\mathrm{BaP}$ adsorbed continuously increased and plateaued at around 20 min. Furthermore, the adsorption of BaP occurred rapidly, with approximately $86.87-88.29 \%$ of $\mathrm{BaP}$ in oils being adsorbed onto LZC within 1 min of contact. This was because a large number of empty adsorption sites were available for adsorption of BaP.

According to the data in Figure 6A, two typical kinetic models, namely pseudo-first-order model and pseudo-second-order model, were used to explain the mechanism of $\mathrm{BaP}$ adsorption on LZC (Figure 6B and 6C). The parameters of the adsorption kinetics were calculated and are listed in Table 2. As shown in Figure 6B and 6C and Table 2, the values of the correlation coefficient $\left(R^{2}\right)$ for the pseudo-second-order model were $\geq 0.999$ for all $\mathrm{BaP}$ concentrations. It meant that the adsorption capacities calculated by the model agreed well with those determined by experiments. Accordingly, the kinetic adsorption of $\mathrm{BaP}$ on LZC can be accurately predicted by the pseudo-second-order
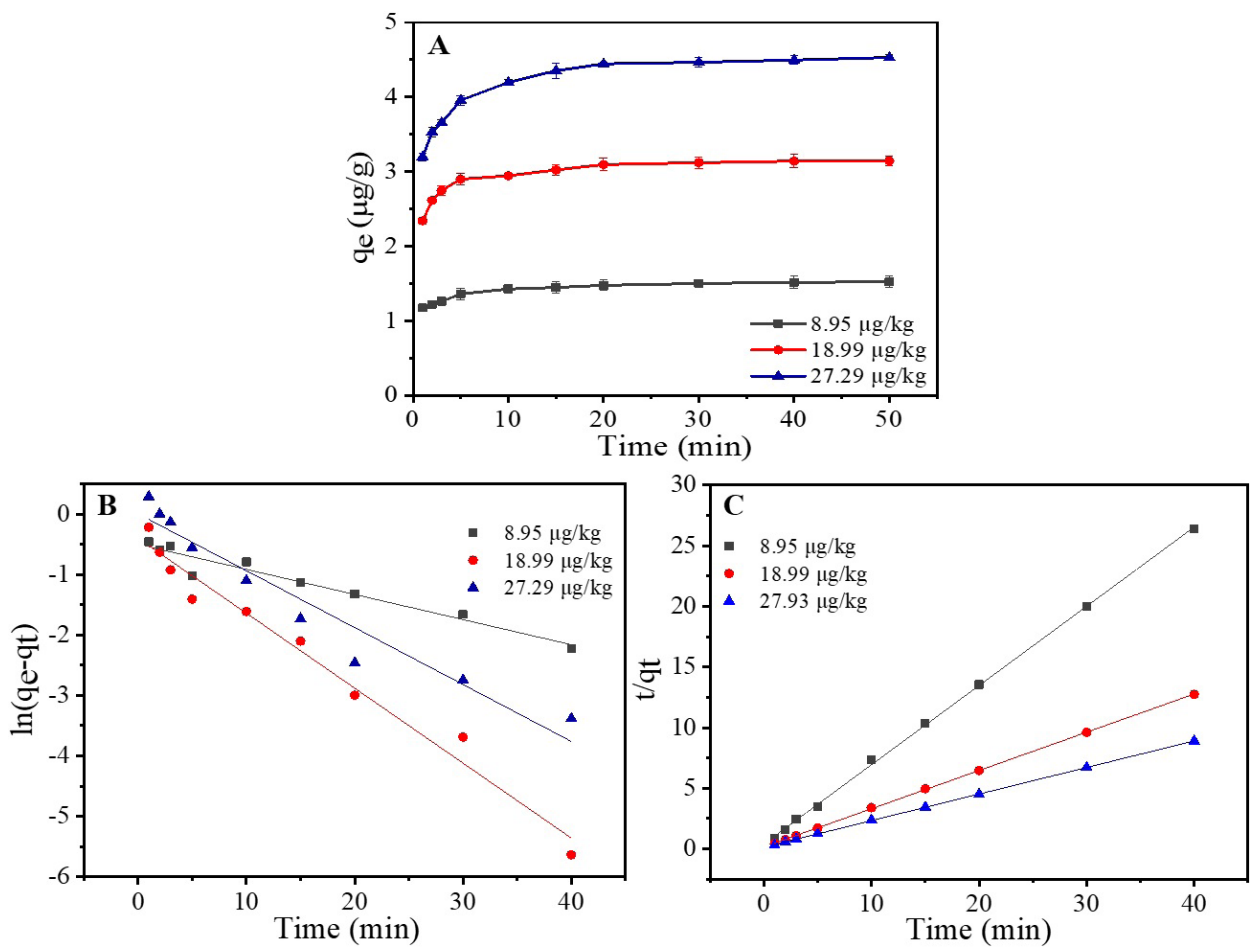

Figure 6. Dynamic adsorption capacity of modified biochar (LZC) with different BaP initial concentrations (A), the linear fit of pseudo-firstorder kinetics (B), and the liner fit of pseudo-second-order kinetics (C).

Table 2. Adsorption kinetic parameters for BaP removal by LZC.

\begin{tabular}{|c|c|c|c|c|c|c|c|}
\hline \multirow{2}{*}{$\mathrm{C}_{0}(\mu \mathrm{g} / \mathrm{kg})$} & \multirow{2}{*}{$\mathrm{q}_{e, \exp }(\mu \mathrm{g} / \mathrm{g})^{\mathrm{c}}$} & \multicolumn{3}{|c|}{ Lagergren-first-order kinetic model $^{\mathrm{a}}$} & \multicolumn{3}{|c|}{ Pseudo-second-order kinetic model ${ }^{\mathrm{b}}$} \\
\hline & & $\mathrm{q}_{e, \text { cal }}(\mu \mathrm{g} / \mathrm{g})$ & $\mathrm{k}_{1}(1 / \mathrm{min})$ & $\mathrm{R}^{2}$ & $\mathrm{q}_{e, \text { cal }}(\mu \mathrm{g} / \mathrm{g})$ & $\mathrm{K}_{2}[\mathrm{~g} /(\mathrm{mg} \cdot \mathrm{min})]$ & $\mathrm{R}^{2}$ \\
\hline 8.95 & 1.52 & 0.61 & 0.0415 & 0.9419 & 1.53 & 1.0254 & 0.9994 \\
\hline 18.99 & 3.14 & 0.67 & 0.1239 & 0.9726 & 3.17 & 0.6123 & 0.9999 \\
\hline 27.93 & 4.53 & 1.00 & 0.0941 & 0.9331 & 4.57 & 0.3275 & 0.9999 \\
\hline
\end{tabular}

${ }^{\mathrm{a}} \mathrm{k}_{1}$ : the first-order rate constant; $\mathrm{q}_{\mathrm{e}, \mathrm{cal}}$-the calculated adsorption capacity; ${ }^{\mathrm{b}} \mathrm{k}_{2}$ : the second-order rate constant; ${ }^{\mathrm{c}} \mathrm{q}_{\mathrm{e}, \mathrm{exp}}$ : the experimental adsorption capacity. 
model. This further indicated that chemical adsorption was the main rate-limiting step in the LZC adsorptions process. Yang et al. (2018) also reported that the adsorption of $\mathrm{BaP}$ on carbon dot-modified magnetic nanocomposites follows a pseudo-second-order kinetic model.

Langmuir and Freundlich models were used to analyze the adsorption data of $\mathrm{BaP}$ onto LZC. The associated constants and correlation coefficients $\left(\mathrm{R}^{2}\right)$ are listed in Table 3 . The highest correlation coefficient $\mathrm{R}^{2} \sim 0.998$, revealed that the adsorption of $\mathrm{BaP}$ on LZC best conformed to the Freundlich model. This result clearly indicates that a multi-layer adsorption process occurred on the surface of the modified biochar (LZC). According to the Freundlich isotherm, the value of $\mathrm{n}$ was $1.161>1$, indicating that $\mathrm{BaP}$ was favorably adsorbed by LZC.

Thermodynamic studies help assess the absorbed/ released heat properties and spontaneity of $\mathrm{BaP}$ adsorption on LZC. Therefore, adsorption experiments were carried out at temperatures of $303.15,343.15,363.15,383.15$, and $403.15^{\circ} \mathrm{K}$. The thermodynamic parameters calculated for adsorption of $\mathrm{BaP}$ on LZC using the Vant Hoff equation are summarized in Table 4 Gibbs free energy change $\left(\Delta \mathrm{G}^{0}\right)$ was negative at different temperatures, implying that the adsorption process of $\mathrm{BaP}$ was spontaneous in nature. The positive value of $\Delta S^{0}$ revealed that an increased disorder at the solid-liquid interface occurred, which also favoured spontaneous adsorption. Moreover, the $\Delta \mathrm{H}^{0}$ for $\mathrm{BaP}$ uptake was positive, indicating that the capture of $\mathrm{BaP}$ by LZC was an endothermic process, and that increased temperature favored $\mathrm{BaP}$ adsorption. The good adsorption of $\mathrm{BaP}$ on $\mathrm{LZC}$ indicated the great potential of this $\mathrm{ZnCl}_{2}$-modified biochar from lignin for applications requiring the removal of $\mathrm{PAH}$, such as $\mathrm{BaP}$, from edible oil.

Table 3. Langmuir and Freundlich isotherm factors for BaP.

\begin{tabular}{cccccc}
\hline \multicolumn{3}{c}{ Langmuir model $^{\mathrm{a}}$} & \multicolumn{3}{c}{ Freundlich model $^{\mathrm{b}}$} \\
\hline $\mathrm{b}(\mathrm{g} / \mathrm{ng})$ & $\mathrm{q}_{\mathrm{m}}(\mu \mathrm{g} / \mathrm{g})$ & $\mathrm{R}^{2}$ & $\mathrm{~K}_{\mathrm{f}}(\mu \mathrm{g} / \mathrm{g})$ & $\mathrm{n}$ & $\mathrm{R}^{2}$ \\
0.069 & 18.814 & 0.8148 & 1.239 & 1.161 & 0.9980 \\
\hline $\begin{array}{l}\text { ab: the Langnuirn adsorption equilibrium constant; } \mathrm{q}_{\mathrm{m}} \text {-the maximum adsorption } \\
\text { capacity; }{ }^{\text {b }} \mathrm{K}_{\mathrm{r}} \text { : the Freundlich adsorption equilibrium constant; } \mathrm{n} \text {-adsorption intensity. }\end{array}$
\end{tabular}

Table 4. Thermodynamic parameters for BaP adsorption by LZC.

\begin{tabular}{cccc}
\hline $\mathrm{T}(\mathrm{K})$ & $\Delta \mathrm{G}^{0}(\mathrm{KJ} / \mathrm{mol})^{\mathrm{a}}$ & $\Delta \mathrm{H}^{0}(\mathrm{KJ} / \mathrm{mol})^{\mathrm{b}}$ & $\begin{array}{c}\Delta \mathrm{S}^{0}[\mathrm{~J} / \\
(\mathrm{mol} \cdot \mathrm{K})]^{\mathrm{c}}\end{array}$ \\
\hline 303.15 & -16.25 & & \\
343.15 & -21.87 & & \\
363.15 & -24.72 & 24.15 & 133.86 \\
383.15 & -27.66 & & \\
403.15 & -29.12 & & \\
\hline
\end{tabular}

${ }^{a} \Delta G^{0}$ : Gibbs free energy; ${ }^{b} \Delta S^{0}$ : entropy; ${ }^{c} \Delta H^{0}$ : enthalpy.

\section{Conclusions}

The effect of $\mathrm{ZnCl}_{2}$-modified biochars from cellulose, hemicellulose and lignin obtained from sesame straw on $\mathrm{BaP}$ removal from edible oil was investigated. The activated biochars had a high surface area and porosity. Among all the modified biochars, the lignin-drived sample LZC presented superior adsorptive capacity, removing around $95 \% \mathrm{BaP}$. The adsorption of $\mathrm{BaP}$ was endothermic and spontaneous. The adsorption kinetics are supported by the pseudo-second-order model, and the adsorption thermodynamics can be best described by the Freundlich model. Over-all, the biochar derived from lignin using $\mathrm{ZnCl}_{2}$ treatment exhibits great potential for practical applications for removing $\mathrm{BaP}$ from edible oil.

\section{Conflict of interest}

The authors declare that there is no conflict of interests regarding the publication of this article.

\section{Acknowledgements}

This study was supported by an earmarked fund from the Modern Agro-industry Technology Research System (CARS14-1-29).

\section{References}

Ahmed, M. J., \& Hameed, B. H. (2018). Adsorption behavior of salicylic acid on biochar as derived from the thermal pyrolysis of barley straws. Journal of Cleaner Production, 195, 1162-1169. http://dx.doi. org/10.1016/j.jclepro.2018.05.257.

Amaral, T. N., Junqueira, L. A., Alves, C. C. O., Oliveira, N. L., Prado, M. E. T., \& Resende, J. V. (2018). Extraction of hydrocolloids from Pereskia Aculeata Miller: reuse of process residue as activated carbon for the pigment-removal phase. Food Science and Technology, 38(Suppl. 1), 77-85. http://dx.doi.org/10.1590/1678-457x.10517.

Banerjee, S., Patti, A. F., Ranganathan, V., \& Arora, A. (2019). Hemicellulose based biorefinery from pineapple peel waste: xylan extraction and its conversion into xylooligosaccharides. Food and Bioproducts Processing, 117, 38-50. http://dx.doi.org/10.1016/j.fbp.2019.06.012.

Brazil, T. R., Gonçalves, M., Junior, M. S. O., \& Rezede, M. C. (2020). A statistical approach to optimize the activated carbon production from Kraft lignin based on conventional and microwave processes. Microporous and Mesoporous Materials, 308, 110485. http://dx.doi. org/10.1016/j.micromeso.2020.110485.

Camargo, M. S. F. O., \& Toledo, M. C. F. (2000). Hidrocarbonetos aromáticos policíclicos em margarina, creme vegetal e maionese. Food Science and Technology, 20(1), 51-55. http://dx.doi.org/10.1590/ S0101-20612000000100011.

Cheng, W., Liu, G., Wang, X., Liu, X., \& Liu, B. (2015). Formation of benzo(a)pyrene in sesame seeds during the roasting process for production of sesame seed oil. Journal of the American Oil Chemists'Society, 92(11-12), 1725-1733. http://dx.doi.org/10.1007/ s11746-015-2734-0.

Choi, S. K., Choe, S. B., \& Kang, S. T. (2014). Reduction of benzo(a) pyrene content in sesame oil by using adsorbents. Journal of the Korean Society of Food Science and Nutrition, 43(4), 564-569. http:// dx.doi.org/10.3746/jkfn.2014.43.4.564.

Choudhary, M., Kumar, R., \& Neogi, S. (2020). Activated biochar derived from Opuntia ficus-indica for the efficient adsorption of malachite 
green dye, $\mathrm{Cu}^{2+}$ and $\mathrm{Ni}^{2+}$ from water. Journal of Hazardous Materials, 392, 122441. http://dx.doi.org/10.1016/j.jhazmat.2020.122441. PMid:32193109.

Cotugno, P., Massari, F., Aresta, A., Zambonin, C., Ragni, R., Monks, K., Avagyan, L., \& Böttcher, J. (2021). Advanced Gel Permeation Chromatography system with increased loading capacity: polycyclic aromatic hydrocarbons detection in olive oil as a case of study. Journal of Chromatography A, 1639, 461920. http://dx.doi.org/10.1016/j. chroma.2021.461920. PMid:33530008.

Danish, M., Hashim, R., Ibrahim, M. N. M., \& Sulaiman, O. (2014). Optimized preparation for large surface area activated carbon from date (Phoenix dactylifera L.) stone biomass. Biomass and Bioenergy, 61, 167-178. http://dx.doi.org/10.1016/j.biombioe.2013.12.008.

Deng, H., Yang, L., Tao, G., \& Dai, J. (2009). Preparation and characterization of activated carbon from cotton stalk by microwave assisted chemical activation: application in methylene blue adsorption from aqueous solution. Journal of Hazardous Materials, 166(2-3), 1514-1521. http://dx.doi.org/10.1016/j.jhazmat.2008.12.080. PMid:19178998.

Deng, J., Xiong, T. Y., Wang, H. Y., Zheng, A. M., \& Wang, Y. (2016). Effects of cellulose, hemicellulose, and lignin on the structure and morphology of porous carbons. ACS Sustainable Chemistry \& Engineering, 4(7), 3750-3756. http://dx.doi.org/10.1021/ acssuschemeng.6b00388.

Guo, C., Han, L., Guo, M., Li, M., Yu, L., \& Yang, Y. (2020). Synthesis of triethylene tetramine-modified water-insoluble corn flour caged in magnetic chitosan resin and its adsorption application for removal of patulin from apple juice. Journal of Food Science, 85(4), 13711379. http://dx.doi.org/10.1111/1750-3841.15112. PMid:32237092.

Hong, D., Zhou, J., Hu, C., Zhou, Q., Mao, J., \& Qin, Q. (2019). Mercury removal mechanism of AC prepared by one-step activation with $\mathrm{ZnCl}_{2}$. Fuel, 235, 326-335. http://dx.doi.org/10.1016/j.fuel.2018.07.103.

Jesus, J. H. F., Cunha, G. D., Cardoso, E. M. C., Mangrich, A. S., \& Romão, L. P. C. (2017). Evaluation of waste biomasses and their biochars for removal of polycyclic aromatic hydrocarbons. Journal of Environmental Management, 200, 186-195. http://dx.doi.org/10.1016/j. jenvman.2017.05.084. PMid:28577454.

Jesus, J. H. F., Matos, T. T. D. S., Cunha, G. D. C., Mangrich, A. S., \& Romão, L. P. C. (2019). Adsorption of aromatic compounds by biochar: influence of the type of tropical biomass precursor. Cellulose, 26(7), 4291-4299. http://dx.doi.org/10.1007/s10570-019-02394-0.

Ji, J., Liu, Y., \& Ma, Y. (2020). Variations of polycyclic aromatic hydrocarbons in vegetable oils during seed roasting pre-treatment. Polycyclic Aromatic Compounds, 6, 1-14. http://dx.doi.org/10.1080 /10406638.2020.1834414.

Ji, J., Liu, Y., Shi, L., Wang, N., \& Wang, X. (2019). Effect of roasting treatment on the chemical composition of sesame oil. LebensmittelWissenschaft + Technologie, 101, 191-200. http://dx.doi.org/10.1016/j. lwt.2018.11.008.

Kazerouni, N., Sinha, R., Hsu, C. H., Greenberg, A., \& Rothman, N. (2001). Analysis of 200 food items for benzo[a]pyrene and estimation of its intake in an epidemiologic study. Food and Chemical Toxicology, 39(5), 423-436. http://dx.doi.org/10.1016/S0278-6915(00)00158-7. PMid:11313108.

Kiralan, S. S., \& Tekin, A. (2020). Reducing polycyclic aromatic hydrocarbons (PAHs) in olive pomace oil using short-path molecular distillation. Food Additives \& Contaminants. Part A, Chemistry, Analysis, Control, Exposure \& Risk Assessment, 37(3), 401. http:// dx.doi.org/10.1080/19440049.2019.1704444. PMid:31917647.

Lee, Y. K., Chung, S., Hwang, S. Y., Lee, S., Eom, K. S., Hong, S. B., Park, G. G., Kim, B. J., Lee, J. J., \& Joh, H. I. (2019). Upcycling of lignin waste to activated carbon for supercapacitor electrode and organic adsorbent. Korean Journal of Chemical Engineering, 36(9), 1543-1547. http://dx.doi.org/10.1007/s11814-019-0340-9.

León-Camacho, M., Viera-Alcaide, I., \& Ruiz-Méndez, M. V. (2003). Elimination of polycyclic aromatic hydrocarbons by bleaching of olive pomace oil. European Journal of Lipid Science and Technology, 105(1), 9-16. http://dx.doi.org/10.1002/ejlt.200390010.

Li, F., Gui, X., Ji, W., \& Zhou, C. (2020). Effect of calcium dihydrogen phosphate addition on carbon retention and stability of biochars derived from cellulose, hemicellulose, and lignin. Chemosphere, 251, 126335. http://dx.doi.org/10.1016/j.chemosphere.2020.126335. PMid:32145573.

Li, J., Li, Y., Wu, Y., \& Zheng, M. (2014). A comparison of biochars from lignin, cellulose and wood as the sorbent to an aromatic pollutant. Journal of Hazardous Materials, 280, 450-457. http:// dx.doi.org/10.1016/j.jhazmat.2014.08.033. PMid:25194813.

Lin, R., Liang, Z., Yang, C., Zhao, Z., \& Cui, F. (2020). Selective adsorption of organic pigments on inorganically modified mesoporosus biochar and its mechanism based on molecular structure. Journal of Colloid and Interface Science, 573, 21-30. http://dx.doi.org/10.1016/j. jcis.2020.03.112. PMid:32268260.

Liu, H., Li, P., Qiu, F., Zhang, T., \& Xu, J. (2020). Controllable preparation of FeOOH/CuO@WBC composite based on water bamboo cellulose applied for enhanced arsenic removal. Food and Bioproducts Processing, 123, 177-187. http://dx.doi.org/10.1016/j.fbp.2020.06.018.

Liu, Y., Ma, S., \& Chen, J. (2018). A novel pyro-hydrochar via sequential carbonization of biomass waste: Preparation, characterization and adsorption capacity. Journal of Cleaner Production, 176, 187-195. http://dx.doi.org/10.1016/j.jclepro.2017.12.090.

Liu, Z., Wang, Z., Tang, S., \& Liu, Z. (2021). Fabrication, characterization and sorption properties of activated biochar from livestock manure via three different approaches. Resources, Conservation and Recycling, 168, 105254. http://dx.doi.org/10.1016/j.resconrec.2020.105254.

Ma, Z., Chen, D., Gu, J., Bao, B., \& Zhang, Q. (2015). Determination of pyrolysis characteristics and kinetics of palm kernel shell using TGA-FTIR and model-free integral methods. Energy Conversion and Management, 89, 251-259. http://dx.doi.org/10.1016/j. enconman.2014.09.074.

Ma, Z., Yang, Y., Wu, Y., Xu, J., Peng, H., Liu, X., Zhang, W., \& Wang, S. (2019). In-depth comparison of the physicochemical characteristics of bio-char derived from biomass pseudo components: Hemicellulose, cellulose, and lignin. Journal of Analytical and Applied Pyrolysis, 140, 195-204. http://dx.doi.org/10.1016/j.jaap.2019.03.015.

Molina-Sabio, M., \& Rodríguez-Reinoso, F. (2004). Role of chemical activation in the development of carbon porosity. Colloids and Surfaces A, Physicochemical and Engineering Aspects, 241(1-3), 1525. http://dx.doi.org/10.1016/j.colsurfa.2004.04.007.

Moserová, M., Kotrbová, V., Aimová, D., Sulc, M., Frei, E., \& Stiborová, M. (2009). Analysis of benzo[a]pyrene metabolites formed by rat hepatic microsomes using high pressure liquid chromatography: optimization of the method. Interdisciplinary Toxicology, 2(4), 239244. http://dx.doi.org/10.2478/v10102-009-0024-0. PMid:21217860.

Oliveira, R. V. M., Lima, J. R. A., Cunha, G. D. M., \& Romão, L. P. C. (2020). Use of eco-friendly magnetic materials for the removal of polycyclic aromatic hydrocarbons and metals from environmental water samples. Journal of Environmental Chemical Engineering, 8(4), 104050. http://dx.doi.org/10.1016/j.jece.2020.104050.

Pan, Y., Deng, Z., Chen, Y., Zhang, W., Yang, Z., Zhao, W., \& Zhang, S. (2017). Determination of benzo[a]pyrene in smoked foods by high-performance liquid chromatography based on magnetic solid phase extraction. Analytical Methods, 9(39), 5763-5768. http://dx.doi. org/10.1039/C7AY01421J. 
Park, J. H., Ok, Y. S., Kim, S. H., Cho, J. S., Heo, J. S., Delaune, R. D., $\&$ Seo, D. C. (2016). Competitive adsorption of heavy metals onto sesame straw biochar in aqueous solutions. Chemosphere, 142, 77-83. http://dx.doi.org/10.1016/j.chemosphere.2015.05.093. PMid:26082184.

Pezoti, O. Jr., Cazetta, A. L., Souza, I. P. A. F., Bedin, K. C., Martins, A. C., Silva, T. L., \& Almedia, V. C. (2014). Adsorption studies of methylene blue onto $\mathrm{ZnCl}_{2}$-activated carbon produced from buriti shells (Mauritia flexuosa L.). Journal of Industrial and Engineering Chemistry, 20(6), 4401-4407. http://dx.doi.org/10.1016/j.jiec.2014.02.007.

Rhee, K. S., \& Bratzler, L. J. (1970). Benzo(a)pyrene in smoked meat products. Journal of Food Science, 35(2), 146-149. http://dx.doi. org/10.1111/j.1365-2621.1970.tb12125.x.

Rojo Camargo, M. C., Antoniolli, P. R., \& Vicente, E. (2012). Evaluation of polycyclic aromatic hydrocarbons content in different stages of soybean oils processing. Food Chemistry, 135(3), 937-942. http:// dx.doi.org/10.1016/j.foodchem.2012.06.031. PMid:22953808.

Shi, L. K., Zheng, L., Jin, Q. Z., \& Wang, X. G. (2017). Effects of adsorption on polycyclic aromatic hydrocarbon, lipid characteristic, oxidative stability, and free radical scavenging capacity of sesame oil. European Journal of Lipid Science and Technology, 119(12), 1700150. http:// dx.doi.org/10.1002/ejlt.201700150.

Shin, B. R., Song, H. W., Lee, J. G., Yoon, H. J., Chung, M. S., \& Kim, Y. S. (2016). Comparison of the contents of benzo(a)pyrene, sesamol and sesamolin, and volatiles in sesame oils according to origins of sesame seeds. Applied Biological Chemistry, 59(1), 129-141. http:// dx.doi.org/10.1007/s13765-015-0138-3.

Smith, M. W., Pecha, B., Helms, G., Scudiero, L., \& Garcia-Perez, M. (2017). Chemical and morphological evaluation of chars produced from primary biomass constituents: cellulose, xylan, and lignin. Biomass and Bioenergy, 104, 17-35. http://dx.doi.org/10.1016/j. biombioe.2017.05.015.

Wan, J., Liu, L., Ayub, K. S., Zhang, W., Shen, G., Hu, S., \& Qian, X. (2020). Characterization and adsorption performance of biochars derived from three key biomass constituents. Fuel, 269, 117142. http://dx.doi.org/10.1016/j.fuel.2020.117142.

Wu, S., Gong, G., Yan, K., Sun, Y., \& Zhang, L. (2020). Polycyclic aromatic hydrocarbons in edible oils and fatty foods: occurrence, formation, analysis, change and control. Advances in Food and Nutrition Research, 93, 59-112. http://dx.doi.org/10.1016/bs.afnr.2020.02.001. PMid:32711866.

Wu, W., Yang, M., Feng, Q., McGrouther, K., Wang, H., Lu, H., \& Chen, Y. (2012). Chemical characterization of rice straw-derived biochar for soil amendment. Biomass and Bioenergy, 47, 268-276. http:// dx.doi.org/10.1016/j.biombioe.2012.09.034.

Xi, Z., \& Chen, B. (2014). The effect of structural compositions on the biosorption of phenanthrene and pyrene by tea leaf residue fractions as model biosorbents. Environmental Science and Pollution Research International, 21(5), 3318-3330. http://dx.doi.org/10.1007/s11356013-2266-9. PMid:24234757.

Yang, D., Tammina, S. K., Li, X., \& Yang, Y. (2019). Enhanced removal and detection of benzo[a]pyrene in environmental water samples using carbon dots-modified magnetic nanocomposites. Ecotoxicology and Environmental Safety, 170, 383-390. http://dx.doi.org/10.1016/j. ecoenv.2018.11.138. PMid:30550968.

Yang, H., Yan, R., Chen, H., Lee, D. H., \& Zheng, C. (2007). Characteristics of hemicellulose, cellulose and lignin pyrolysis. Fuel, 86(12-13), 1781-1788. http://dx.doi.org/10.1016/j.fuel.2006.12.013.

Yang, K., Jiang, Y., Yang, J., \& Lin, D. (2018). Correlations and adsorption mechanisms of aromatic compounds on biochars produced from various biomass at $700{ }^{\circ} \mathrm{C}$. Environmental Pollution, 233, 64-70. http://dx.doi.org/10.1016/j.envpol.2017.10.035. PMid:29053999.

Yebra-Pimentel, I., Fernández-González, R., Martínez-Carballo, E., \& Simal-Gándara, J. (2014). Optimization of purification processes to remove polycyclic aromatic hydrocarbons (PAHs) in polluted raw fish oils. The Science of the Total Environment, 470-471(2), 917-924. http://dx.doi.org/10.1016/j.scitotenv.2013.10.061. PMid:24231673. 